\title{
Optimization of Solar CCHP Systems with Collector Enhanced by Porous Media and Nanofluid
}

\author{
Navid Tonekaboni $\left(\mathbb{D},{ }^{1}\right.$ Mahdi Feizbahr $\mathbb{D}^{2}{ }^{2}$ Nima Tonekaboni $\mathbb{D}^{1},{ }^{1}$ Guang-Jun Jiang $\left(\mathbb{D},{ }^{3,4}\right.$ \\ and Hong-Xia Chen iD 3,4 \\ ${ }^{1}$ Mechanical-Energy Conversion, Islamic Azad University, Nour Branch, Nour, Iran \\ ${ }^{2}$ School of Civil Engineering, Department of Engineering, University Sains Malaysia, Pulau Penang, Malaysia \\ ${ }^{3}$ School of Mechanical Engineering, Inner Mongolia University of Technology, Hohhot, Inner Mongolia 010051, China \\ ${ }^{4}$ Inner Mongolia Key Laboratory of Advanced Manufacturing Technology, Hohhot, Inner Mongolia 010051, China
}

Correspondence should be addressed to Mahdi Feizbahr; m.feizbahr@gmail.com and Guang-Jun Jiang; jianggj_2003@163.com

Received 5 March 2021; Revised 20 March 2021; Accepted 1 April 2021; Published 16 April 2021

Academic Editor: Noorbakhsh Amiri Golilarz

Copyright (C) 2021 Navid Tonekaboni et al. This is an open access article distributed under the Creative Commons Attribution License, which permits unrestricted use, distribution, and reproduction in any medium, provided the original work is properly cited.

\begin{abstract}
The low efficiency of solar collectors can be mentioned as one of the problems in solar combined cooling, heating, and power (CCHP) cycles. For improving solar systems, nanofluid and porous media are used in solar collectors. One of the advantages of using porous media and nanoparticles is to absorb more energy under the same conditions. In this research, a solar combined cooling, heating, and power (SCCHP) system has been optimized by porous media and nanofluid for generating electricity, cooling, and heating of a $600 \mathrm{~m}^{2}$ building in a warm and dry region with average solar radiation of $\mathrm{Ib}=820 \mathrm{w} / \mathrm{m}^{2}$ in Iran. In this paper, the optimal amount of nanofluid in porous materials has been calculated to the extent that no sediment is formed. In this study, solar collectors were enhanced with copper porous media (95\% porosity) and $\mathrm{CuO}$ and $\mathrm{Al}_{2} \mathrm{O}_{3}$ nanofluids. $0.1 \%-0.6 \%$ of the nanofluids were added to water as working fluids; it is found that $0.5 \%$ of the nanofluids lead to the highest energy and exergy efficiency enhancement in solar collectors and SCCHP systems. Maximum energy and exergy efficiency of parabolic thermal collector (PTC) riches in this study are $74.19 \%$ and $32.6 \%$, respectively. Figure 1 can be mentioned as a graphical abstract for accurately describing the cycle of solar CCHP.
\end{abstract}

\section{Introduction}

Due to the increase in energy consumption, the use of clean energy is one of the important goals of human societies. In the last four decades, the use of cogeneration cycles has increased significantly due to high efficiency. Among clean energy, the use of solar energy has become more popular due to its greater availability [1]. Low efficiency of energy production, transmission, and distribution system makes a new system to generate simultaneously electricity, heating, and cooling as an essential solution to be widely used. The low efficiency of the electricity generation, transmission, and distribution system makes the CCHP system a basic solution to eliminate waste of energy. CCHP system consists of a prime mover (PM), a power generator, a heat recovery system (produce extra heating/cooling/power), and thermal energy storage (TES) [2]. Solar combined cooling, heating, and power (SCCHP) has been started three decades ago. SCCHP is a system that receives its propulsive force from solar energy; in this cycle, solar collectors play the role of propulsive for generating power in this system [3].

Increasing the rate of energy consumption in the whole world because of the low efficiency of energy production, transmission, and distribution system causes a new cogeneration system to generate electricity, heating, and cooling energy as an essential solution to be widely used. Building energy utilization fundamentally includes power required for lighting, home electrical appliances, warming and cooling of building inside, and boiling water. Domestic 
usage contributes to an average of $35 \%$ of the world's total energy consumption [4].

Due to the availability of solar energy in all areas, solar collectors can be used to obtain the propulsive power required for the CCHP cycle. Solar energy is the main source of energy in renewable applications. For selecting a suitable area to use solar collectors, annual sunshine hours, the number of sunny days, minus temperature and frosty days, and the windy status of the region are essentially considered [5]. Iran, with an average of more than 300 sunny days, is one of the suitable countries to use solar energy. Due to the fact that most of the solar radiation is in the southern regions of Iran, also the concentration of cities is low in these areas, and transmission lines are far apart, one of the best options is to use CCHP cycles based on solar collectors [6]. One of the major problems of solar collectors is their low efficiency [7]. Low efficiency increases the area of collectors, which increases the initial cost of solar systems and of course increases the initial payback period. To increase the efficiency of solar collectors and improve their performance, porous materials and nanofluids are used to increase their workability.

There are two ways to increase the efficiency of solar collectors and mechanical and fluid improvement. In the first method, using porous materials or helical filaments inside the collector pipes causes turbulence of the flow and increases heat transfer. In the second method, using nanofluids or salt and other materials increases the heat transfer of water. The use of porous materials has grown up immensely over the past twenty years. Porous materials, especially copper porous foam, are widely used in solar collectors. Due to the high contact surface area, porous media are appropriate candidates for solar collectors [8]. A number of researchers investigated Solar System performance in accordance with energy and exergy analyses. Zhai et al. [9] reviewed the performance of a small solar-powered system in which the energy efficiency was $44.7 \%$ and the electrical efficiency was $16.9 \%$.

Abbasi et al. [10] proposed an innovative multiobjective optimization to optimize the design of a cogeneration system. Results showed the CCHP system based on an internal diesel combustion engine was the applicable alternative at all regions with different climates. The diesel engine can supply the electrical requirement of $31.0 \%$ and heating demand of $3.8 \%$ for building.

Jiang et al. [11] combined the experiment and simulation together to analyze the performance of a cogeneration system. Moreover, some research focused on CCHP systems using solar energy. It integrated sustainable and renewable technologies in the CCHP, like PV, Stirling engine, and parabolic trough collector (PTC) [2, 12-15].

Wang et al. [16] optimized a cogeneration solar cooling system with a Rankine cycle and ejector to reach the maximum total system efficiency of $55.9 \%$. Jing et al. analyzed a big-scale building with the SCCHP system and auxiliary heaters to produced electrical, cooling, and heating power. The maximum energy efficiency reported in their work is $46.6 \%$ [17]. Various optimization methods have been used to improve the cogeneration system, minimum system size, and performance, such as genetic algorithm $[18,19]$.

Hirasawa et al. [20] investigated the effect of using porous media to reduce thermal waste in solar systems. They used the high-porosity metal foam on top of the flat plate solar collector and observed that thermal waste decreased by $7 \%$ due to natural heat transfer. Many researchers study the efficiency improvement of the solar collector by changing the collector's shapes or working fluids. However, the most effective method is the use of nanofluids in the solar collector as working fluid [21]. In the experimental study done by Jouybari et al. [22], the efficiency enhancement up to $8.1 \%$ was achieved by adding nanofluid in a flat plate collector. In this research, by adding porous materials to the solar collector, collector efficiency increased up to $92 \%$ in a low flow regime. Subramani et al. [23] analyzed the thermal performance of the parabolic solar collector with $\mathrm{Al}_{2} \mathrm{O}_{3}$ nanofluid. They conducted their experiments with Reynolds number range 2401 to 7202 and mass flow rate 0.0083 to $0.05 \mathrm{~kg} / \mathrm{s}$. The maximum efficiency improvement in this experiment was $56 \%$ at $0.05 \mathrm{~kg} / \mathrm{s}$ mass flow rate.

Shojaeizadeh et al. [24] investigated the analysis of the second law of thermodynamic on the flat plate solar collector using $\mathrm{Al}_{2} \mathrm{O}_{3}$ /water nanofluid. Their research showed that energy efficiency rose up to $1.9 \%$ and the exergy efficiency increased by a maximum of $0.72 \%$ compared to pure water. Tiwari et al. [25] researched on the thermal performance of solar flat plate collectors for working fluid water with different nanofluids. The result showed that using 1.5\% (optimum) particle volume fraction of $\mathrm{Al}_{2} \mathrm{O}_{3}$ nanofluid as an absorbing medium causes the thermal efficiency to enhance up to $31.64 \%$.

The effect of porous media and nanofluids on solar collectors has already been investigated in the literature but the SCCHP system with a collector embedded by both porous media and nanofluid for enhancing the ratio of nanoparticle in nanofluid for preventing sedimentation was not discussed. In this research, the amount of energy and exergy of the solar CCHP cycles with parabolic solar collectors in both base and improved modes with a porous material (copper foam with 95\% porosity) and nanofluid with different ratios of nanoparticles was calculated. In the first step, it is planned to design a CCHP system based on the required load, and, in the next step, it will analyze the energy and exergy of the system in a basic and optimize mode. In the optimize mode, enhanced solar collectors with porous material and nanofluid in different ratios $(0.1 \%-0.7 \%)$ were used to optimize the ratio of nanofluids to prevent sedimentation.

\section{Cycle Description}

CCHP is one of the methods to enhance energy efficiency and reduce energy loss and costs. The SCCHP system used a solar collector as a prime mover of the cogeneration system and assisted the boiler to generate vapor for the turbine. Hot water flows from the expander to the absorption chiller in summer or to the radiator or fan coil in winter. Finally, 
before the hot water wants to flow back to the storage tank, it flows inside a heat exchanger for generating domestic hot water [26].

For designing of solar cogeneration system and its analysis, it is necessary to calculate the electrical, heating (heating load is the load required for the production of warm water and space heating), and cooling load required for the case study considered in a residential building with an area of $600 \mathrm{~m}^{2}$ in the warm region of Iran (Zahedan). In Table 1, the average of the required loads is shown for the different months of a year (average of electrical, heating, and cooling load calculated with CARRIER software).

According to Table 1, the maximum magnitude of heating, cooling, and electrical loads is used to calculate the cogeneration system. The maximum electric load is $96 \mathrm{~kW}$, the maximum amount of heating load is $62 \mathrm{~kW}$, and the maximum cooling load is $118 \mathrm{~kW}$. Since the calculated loads are average, all loads increased up to $10 \%$ for the confidence coefficient. With the obtained values, the solar collector area and other cogeneration system components are calculated. The cogeneration cycle is capable of producing $105 \mathrm{~kW}$ electric power, $140 \mathrm{~kW}$ cooling capacity, and $100 \mathrm{~kW}$ heating power.

2.1. System Analysis Equations. An analysis is done by considering the following assumptions:

(1) The system operates under steady-state conditions

(2) The system is designed for the warm region of Iran (Zahedan) with average solar radiation $\mathrm{Ib}=820 \mathrm{w} / \mathrm{m}^{2}$

(3) The pressure drops in heat exchangers, separators, storage tanks, and pipes are ignored

(4) The pressure drop is negligible in all processes and no expectable chemical reactions occurred in the processes

(5) Potential, kinetic, and chemical exergy are not considered due to their insignificance

(6) Pumps have been discontinued due to insignificance throughout the process

(7) All components are assumed adiabatic

Schematic shape of the cogeneration cycle is shown in Figure 1 and all data are given in Table 2.

Based on the first law of thermodynamic, energy analysis is based on the following steps.

First of all, the estimated solar radiation energy on collector has been calculated:

$$
\dot{Q}_{s}=A \times I_{b} \times \alpha,
$$

where $\alpha$ is the heat transfer enhancement coefficient based on porous materials added to the collector's pipes. The coefficient $\alpha$ is increased by the porosity percentage, the type of porous material (in this case, copper with a porosity percentage of 95), and the flow of fluid to the collector equation.

Collector efficiency is going to be calculated by the following equation [9]:
TABLE 1: The average amount of electric charges, heating load, and cooling load used in the different months of the year in the city of Zahedan for a residential building with $600 \mathrm{~m}^{2}$.

\begin{tabular}{lccc}
\hline Month & $\begin{array}{c}\text { Electrical load } \\
(\mathrm{kW})\end{array}$ & $\begin{array}{c}\text { Heating load } \\
(\mathrm{kW})\end{array}$ & $\begin{array}{c}\text { Cooling load } \\
(\mathrm{kW})\end{array}$ \\
\hline April & 73 & 51 & 16 \\
May & 78 & 28 & 38 \\
June & 89 & 13 & 56 \\
July & 92 & 8 & 99 \\
August & 96 & 7 & 118 \\
September & 78 & 9 & 96 \\
October & 70 & 16 & 51 \\
November & 58 & 28 & 35 \\
December & 52 & 36 & 11 \\
January & 54 & 53 & 0 \\
February & 60 & 62 & 0 \\
March & 67 & 59 & 13 \\
\hline
\end{tabular}

$$
\eta_{c}=0.7-0.41 \frac{\left(T_{1}+T_{6}\right) / 2-T_{a}}{I_{b}} .
$$

Total energy received by the collector is given by [9]

$$
\dot{Q}_{c}=A I_{b} \eta_{c}
$$

Also, the auxiliary boiler heat load is [2]

$$
\dot{Q}_{b}=\left[\left(h_{1}-h_{6}\right) \dot{m}_{\mathrm{st}}-A I_{b} \eta_{c}\right] \times \alpha .
$$
by $[2]$

Energy consumed from vapor to expander is calculated

$$
\dot{\mathrm{Q}}_{\exp }=\dot{\mathrm{m}}_{\mathrm{st}} \eta_{\exp }\left[h_{1}-\left(h_{2}^{\prime}\left(1-x_{2 s}\right)+h_{2}^{\prime \prime} x_{2 s}\right)\right] .
$$

The power output form by the screw expander [9]:

$$
\dot{w}_{\exp }=\eta_{\exp } \dot{Q}_{\exp }
$$

The efficiency of the expander is $80 \%$ in this case [11].

In this step, cooling and heating loads were calculated and then, the required heating load to reach sanitary hot water will be calculated as follows:

First step: calculating the cooling load with the following equation [9]:

$$
\dot{Q}_{\text {cool }}=-5.45358+0.17373 T_{7} \text {. }
$$

Second step: calculating heating loads [9]:

$$
\dot{Q}_{\text {Heat }}=\eta_{\text {HE }}\left(T_{2}-T_{8}\right) \dot{m}_{\text {heat }} C_{p . \mathrm{W}} .
$$

Then, calculating the required loud for sanitary hot water will be [9]

$$
\dot{\mathrm{Q}}_{\text {hotwater }}=\eta_{\mathrm{HE}}\left(T_{4}-T_{10}\right) \dot{m}_{\text {hotwater }} C_{\mathrm{pW}} .
$$

According to the above-mentioned equations, efficiency is [9] 


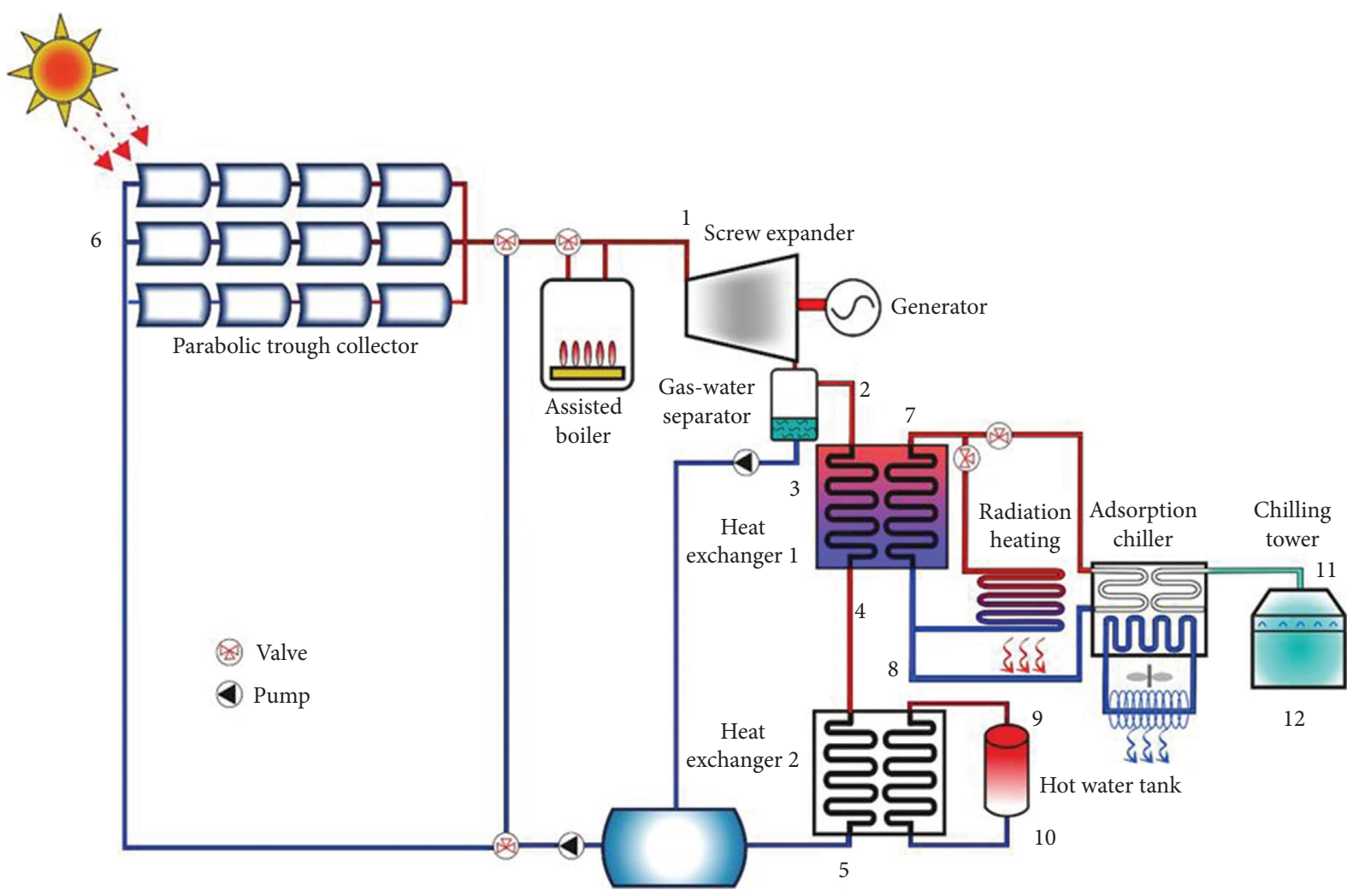

FIGURE 1: Schematic shape of the cogeneration cycle.

TABLE 2: Temperature and humidity of different points of system.

\begin{tabular}{|c|c|c|c|c|c|c|c|}
\hline State & $\begin{array}{l}\text { Temperature } \\
\text { summer }\left(c^{\circ}\right)\end{array}$ & $\begin{array}{c}\text { Temperature } \\
\text { winter }\left(c^{\circ}\right)\end{array}$ & $\begin{array}{l}\text { Humidity } \\
(\%)\end{array}$ & $\begin{array}{c}\text { Enthalpy- } \\
\text { summer (kj/kg) }\end{array}$ & $\begin{array}{c}\text { Enthalpy-winter } \\
(\mathrm{kj} / \mathrm{kg})\end{array}$ & $\begin{array}{c}\text { Entropy- } \\
\text { summer }(\mathrm{kj} / \mathrm{kg})\end{array}$ & $\begin{array}{c}\text { Entropy-winter } \\
(\mathrm{kj} / \mathrm{kg})\end{array}$ \\
\hline 1 & 110 & 110 & 0.1 & 946.7 & 946.7 & 2.58 & 2.58 \\
\hline 2 & 92 & 92 & 0.23 & 913 & 913 & 2.63 & 2.63 \\
\hline 3 & 85 & 85 & - & 367.9 & 367.9 & 1.17 & 1.17 \\
\hline 4 & 90 & 90 & 0.04 & 526 & 526 & 1.62 & 1.62 \\
\hline 5 & 85 & 85 & - & 367.9 & 367.9 & 1.17 & 1.17 \\
\hline 6 & 85 & 85 & - & 367.9 & 367.9 & 1.17 & 1.17 \\
\hline 7 & 88.8 & 45 & - & 372 & 188.4 & 1.18 & 0.64 \\
\hline 8 & 82.1 & 83.3 & - & 343.7 & 348.6 & 1.10 & 1.11 \\
\hline 9 & - & 10 & - & 42 & 42 & 0.15 & 0.15 \\
\hline 10 & - & 78 & - & 326.5 & 326.5 & 1.05 & 1.05 \\
\hline
\end{tabular}

$$
\eta_{e}= \begin{cases}\frac{\dot{W}_{E}+\dot{Q}_{\text {cool }}}{\dot{Q}_{S}+\dot{Q}_{G}} & \text { summer } \\ \frac{\dot{W}_{E}+\dot{Q}_{\text {heat }}+\dot{Q}_{\text {hotwater }}}{\dot{Q}_{S}+\dot{Q}_{G}}, & \text { winter. }\end{cases}
$$

In the third step, calculated exergy analysis as follows.

First, the received exergy collector from the sun is calculated [9]:

$$
\dot{\mathrm{Ex}}_{s}=\left[1-\frac{4}{3} \frac{\mathrm{Ta}}{\mathrm{Ts}}(1-0.28 \ln f)\right] \dot{Q}_{S}, \quad f=1.3 \times 10^{-5} \text {. }
$$

In the previous equation, $f$ is the constant of air dilution. The received exergy from the collector is [9]

$$
\dot{\mathrm{Ex}}_{c}=\left(h_{1}-h_{6}\right) \dot{m}_{\mathrm{St}}-(\mathrm{Ta}+273.15)\left(S_{1}-S_{6}\right) \dot{m}_{\mathrm{St}} .
$$

In the case of using natural gas in an auxiliary heater, the gas exergy is calculated from the following equation [12]:

$$
\dot{\mathrm{Ex}}_{G}=0.95 \dot{Q}_{g} \text {. }
$$

Delivering exergy from vapor to expander is calculated with the following equation [9]:

$$
\dot{\mathrm{Ex}}_{\exp }=\left(h_{1}-h_{2}\right) \dot{m}_{\mathrm{St}}-(T a+273.15)\left(S_{1}-S_{2}\right) \dot{m}_{\mathrm{St}} .
$$

In the fourth step, the exergy in cooling and heating is calculated by the following equation: 
Cooling exergy in summer is calculated [9]:

$$
\dot{E}_{\text {xcool }}=\dot{Q}_{\text {cool }}\left(\frac{T_{a}+273.15}{T_{\text {cool }}+273.15}-1\right) \text {. }
$$

Heating exergy in winter is calculated [9]:

$$
\dot{E}_{\text {xheat }}=\dot{Q}_{\text {heat }}\left(1-\frac{T_{a}+273.15}{T_{\text {heat }}+273.15}\right) \text {. }
$$

In the last step based on thermodynamic second law, exergy efficiency has been calculated from the following equation and the above-mentioned calculated loads [9]:

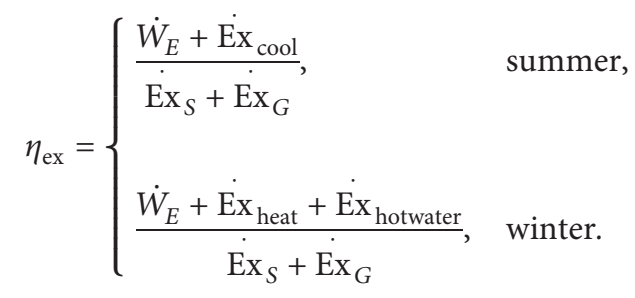

\section{Porous Media}

The porous medium that filled the test section is copper foam with a porosity of $95 \%$. The foams are determined in Figure 2 and also detailed thermophysical parameters and dimensions are shown in Table 3.

In solar collectors, copper porous materials are suitable for use at low temperatures and have an easier and faster manufacturing process than ceramic porous materials. Due to the high coefficient conductivity of copper, the use of copper metallic foam to increase heat transfer is certainly more efficient in solar collectors.

Porous media and nanofluid in solar collector's pipes were simulated in FLOW-3D software using the finite-difference method [27]. Nanoparticles $\mathrm{Al}_{2} \mathrm{O}_{3}$ and $\mathrm{CUO}$ are mostly used in solar collector enhancement. In this research, different concentrations of nanofluid are added to the parabolic solar collectors with porous materials (copper foam with porosity of $95 \%$ ) to achieve maximum heat transfer in the porous materials before sedimentation. After analyzing PTC pipes with the nanofluid flow in FLOW-3D software, for energy and exergy efficiency analysis, Carrier software results were used as EES software input. Simulation PTC with porous media inside collector pipe and nanofluids sedimentation is shown in Figure 3.

3.1. Nano Fluid. In this research, copper and silver nanofluids $\left(\mathrm{Al}_{2} \mathrm{O}_{3}, \mathrm{CuO}\right)$ have been added with percentages of $0.1 \%-0.7 \%$ as the working fluids. The nanoparticle properties are given in Table 4. Also, system constant parameters are presented in Table 4, which are available as default input in the EES software.

System constant parameters for input in the software are shown in Table 5.

The thermal properties of the nanofluid can be obtained from equations (18)-(21). The basic fluid properties are

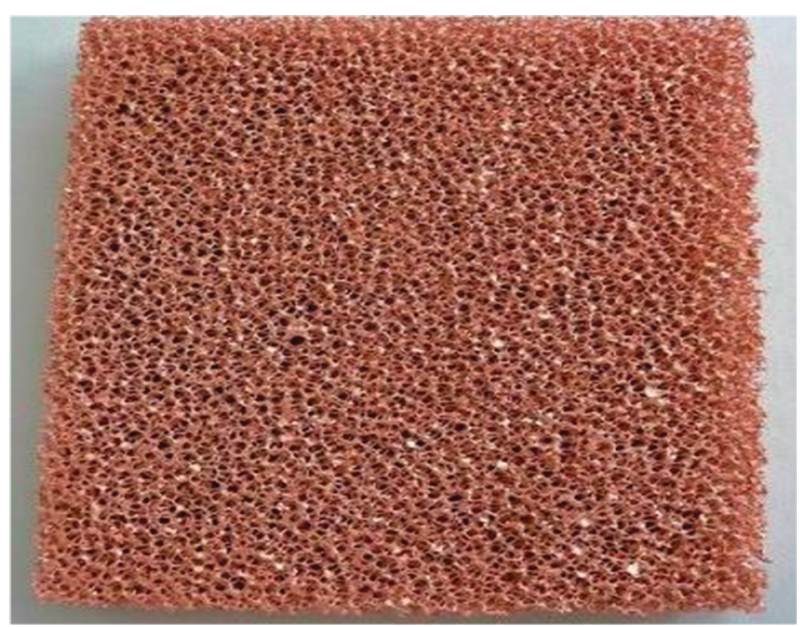

FIgURE 2: Copper foam with a porosity of $95 \%$.

TABle 3: Thermophysical parameters and dimensions of copper foam.

\begin{tabular}{lc}
\hline Material & Copper \\
\hline Porosity & 0.95 \\
Permeability, $K\left(\mathrm{~m}^{2}\right)$ & $1.37 \times 10^{-11}$ \\
Diameter of porous media, $d p(\mathrm{~mm})$ & 31 \\
Thermal conductivity $(\mathrm{W} /(\mathrm{m} . \mathrm{k}))$ & 398 \\
\hline
\end{tabular}

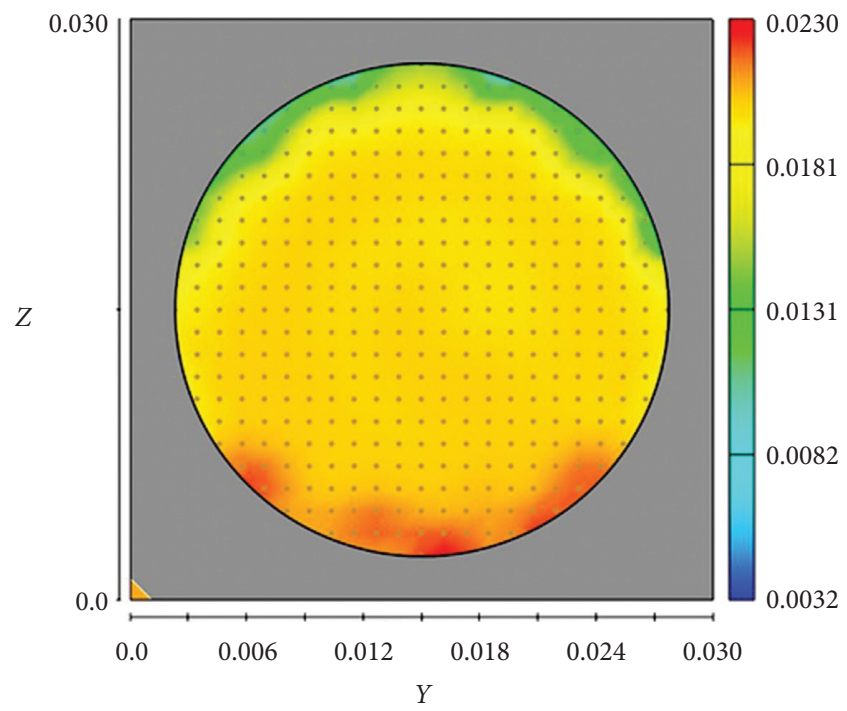

FIGURE 3: Simulation PTC pipes enhanced with copper foam and nanoparticles in FLOW-3D software.

Table 4: Properties of the nanoparticles [9].

\begin{tabular}{lcccc}
\hline Particle & $\rho\left(\mathrm{kg} / \mathrm{m}^{3}\right)$ & $k(\mathrm{~W} / \mathrm{mk})$ & $c p(\mathrm{kj} / \mathrm{kgk})$ & Density $\left(\mathrm{kg} / \mathrm{m}^{3}\right)$ \\
\hline $\mathbf{A l}_{\mathbf{2}} \mathbf{O}_{\mathbf{3}}$ & 3970 & 40 & 0.765 & 3950 \\
$\mathbf{C u O}$ & 6320 & 77 & 0.532 & 6310 \\
\hline
\end{tabular}

indicated by the index $(b f)$ and the properties of the nanoparticle silver with the index $(n p)$. 
TABLE 5: System constant parameters.

\begin{tabular}{lc}
\hline Parameters & Values \\
\hline Average ambient temperature $\left(T_{\mathrm{am}}\right)$ & $26^{\circ} \mathrm{C}$ \\
Solar beam irradiation $\left(I_{b}\right)$ & $0.82 \mathrm{kw} / \mathrm{m}^{2}$ \\
Temperature difference in recuperator $\left(\Delta T_{\mathrm{rc}}\right)$ & $22^{\circ} \mathrm{C}$ \\
Electromechanical efficiency of the generator $\left(\eta_{\mathrm{mg}}\right)$ & $95 \%$ \\
Turbine isentropic efficiency $\left(\eta_{\mathrm{is}}\right)$ & $80 \%$ \\
Heat exchanger efficiency $\left(\eta_{\mathrm{he}}\right)$ & $90 \%$ \\
Cover emittance $\left(\varepsilon_{\mathrm{c}}\right)$ & 0.92 \\
Average wind speed $\left(V_{\text {wind }}\right)$ & $1.5 \mathrm{~m} / \mathrm{s}$ \\
Room temperature in summer $\left(T_{\mathrm{rs}}\right)$ & $20^{\circ} \mathrm{C}$ \\
Room temperature in winter $\left(T_{\mathrm{rw}}\right)$ & $24^{\circ} \mathrm{C}$ \\
Sun temperature $\left(T_{\mathrm{sun}}\right)$ & $5770 \mathrm{~K}$ \\
\hline
\end{tabular}

The density of the mixture is shown in the following equation [28]:

$$
\rho_{n f}=\rho_{b f} \cdot(1-\varphi)+\rho_{n p} \cdot \varphi,
$$

where $\rho$ is density and $\phi$ is the nanoparticles volume fraction.

The specific heat capacity is calculated from the following equation [29]:

$$
c_{p . n f}=\frac{\rho_{b f \cdot(1-\phi)}}{\rho_{b f}} \cdot c_{p . b f}+\frac{\rho_{n p \cdot \phi}}{\rho_{n f}} \cdot c_{p . n p} .
$$

The thermal conductivity of the nanofluid is calculated from the following equation [29]:

$$
k_{n f}=k_{b f} \cdot \frac{k_{n p}+2 \cdot k_{b f}+2 \cdot\left(k_{n p}-k_{b f}\right) \cdot(1+\beta)^{3} \cdot \phi}{k_{n p}+2 \cdot k_{b f}-\left(k_{n p}-k_{b f}\right) \cdot(1+\beta)^{3} \cdot \phi} .
$$

The parameter $\beta$ is the ratio of the nanolayer thickness to the original particle radius and, usually, this parameter is taken equal to 0.1 for the calculated thermal conductivity of the nanofluids.

The mixture viscosity is calculated as follows [30]:

$$
\mu_{n f}=\mu_{b f} \cdot\left(1+2.5 \cdot \phi+6.5 \cdot \phi^{2}\right) .
$$

In all equations, instead of water properties, working fluids with nanofluid are used. All of the above equations and parameters are entered in the EES software for calculating the energy and exergy of solar collectors and the SCCHP cycle. All calculation repeats for both nanofluids with different concentrations of nanofluid in the solar collector's pipe.

\section{Results and Discussion}

In the present study, relations were written according to Wang et al. [16] and the system analysis was performed to ensure the correctness of the code. The energy and exergy charts are plotted based on the main values of the paper and are shown in Figures 4 and 5. The error rate in this simulation is $1.07 \%$.

We may also investigate the application of machine learning paradigms [31-41] and various hybrid, advanced optimization approaches that are enhanced in terms of exploration and intensification [42-55], and intelligent model studies [56-61] as well, for example, methods such as particle swarm optimizer (PSO) [60, 62], differential search (DS) [63], ant colony optimizer (ACO) [61, 64, 65], Harris hawks optimizer (HHO) [66], grey wolf optimizer (GWO) $[53,67]$, differential evolution (DE) $[68,69]$, and other fusion and boosted systems [41, 46, 48, 50, 54, 55, 70, 71].

At the first step, the collector is modified with porous copper foam material. 14 cases have been considered for the analysis of the SCCHP system (Table 6). It should be noted that the adding of porous media causes an additional pressure drop inside the collector [9, 22-26, 30, 72]. All fourteen cases use copper foam with a porosity of 95 percent. To simulate the effect of porous materials and nanofluids, the first solar PTC pipes have been simulated in the FLOW-3D software and then porous media (copper foam with porosity of $95 \%)$ and fluid flow with nanoparticles $\left(\mathrm{AL}_{2} \mathrm{O}_{3}\right.$ and $\left.\mathrm{CUO}\right)$ are generated in the software. After analyzing PTC pipes in FLOW-3D software, for analyzing energy and exergy efficiency, software outputs were used as EES software input for optimization ratio of sedimentation and calculating energy and exergy analyses.

In this research, an enhanced solar collector with both porous media and Nanofluid is investigated. In the present study, $0.1-0.5 \% \mathrm{CuO}$ and $\mathrm{Al}_{2} \mathrm{O}_{3}$ concentration were added to the collector fully filled by porous media to achieve maximum energy and exergy efficiencies of solar CCHP systems. All steps of the investigation are shown in Table 6 .

Energy and exergy analyses of parabolic solar collectors and SCCHP systems are shown in Figures 6 and 7.

Results show that the highest energy and exergy efficiencies are $74.19 \%$ and $32.6 \%$, respectively, that is achieved in Step 12 (parabolic collectors with filled porous media and $\left.0.5 \% \mathrm{Al}_{2} \mathrm{O}_{3}\right)$. In the second step, the maximum energy efficiency of SCCHP systems with fourteen steps of simulation are shown in Figure 7.

In the second step, where $0.1,-0.6 \%$ of the nanofluids were added, it is found that $0.5 \%$ leads to the highest energy and exergy efficiency enhancement in solar collectors and SCCHP systems. Using concentrations more than $0.5 \%$ leads to sediment in the solar collector's pipe and a decrease of porosity in the pipe [73]. According to Figure 7, maximum energy and exergy efficiencies of SCCHP are achieved in Step 12. In this step energy efficiency is $54.49 \%$ and exergy efficiency is $18.29 \%$. In steps 13 and 14 , with increasing concentration of CUO and $\mathrm{Al}_{2} \mathrm{O}_{3}$ nanofluid solution in porous materials, decreasing of energy and exergy efficiency of PTC and SCCHP system at the same time happened. This decrease in efficiency is due to the formation of sediment in the porous material. Calculations and simulations have shown that porous materials more than $0.5 \%$ nanofluids inside the collector pipe cause sediment and disturb the porosity of porous materials and pressure drop and reduce the coefficient of performance of the cogeneration system. Most experience showed that $\mathrm{CUO}$ and $\mathrm{AL}_{2} \mathrm{O}_{3}$ nanofluids with less than $0.6 \%$ percent solution are used in the investigation on the solar collectors at low temperatures and discharges [74]. One of the important points of this research is that the best ratio of nanofluids in the solar collector with a 


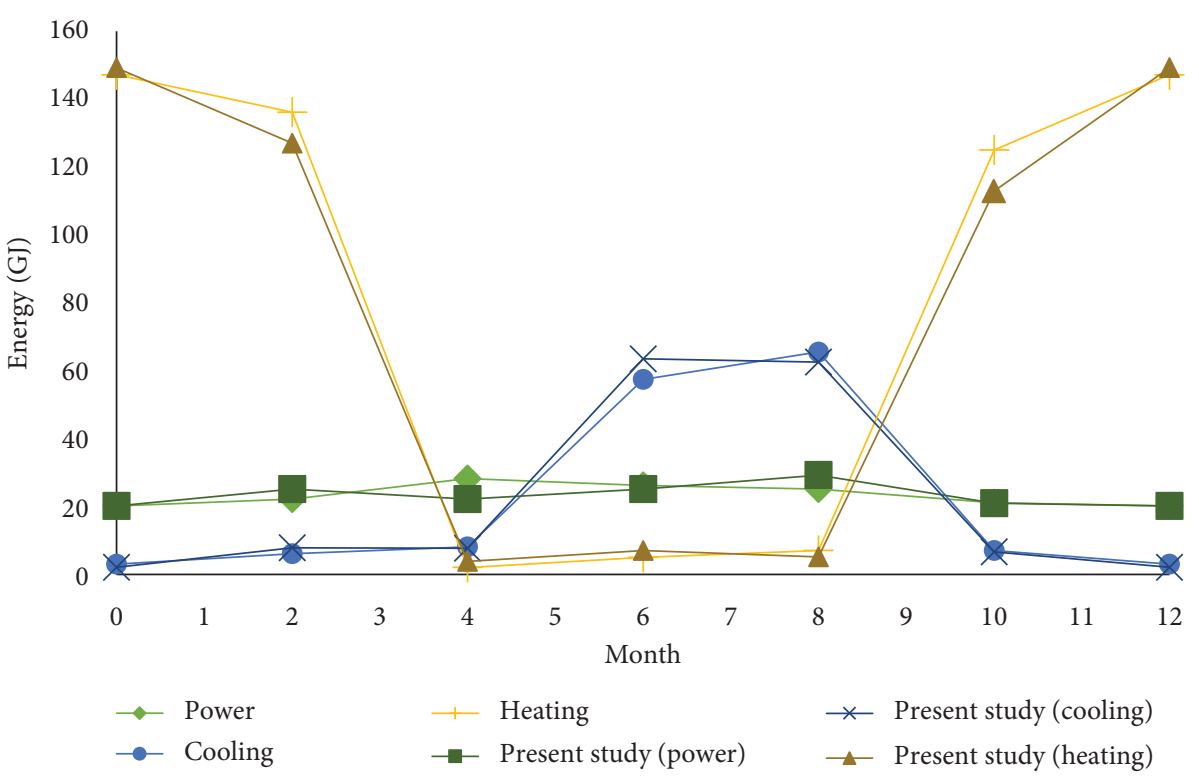

FIgURe 4: Verification charts of energy analysis results.

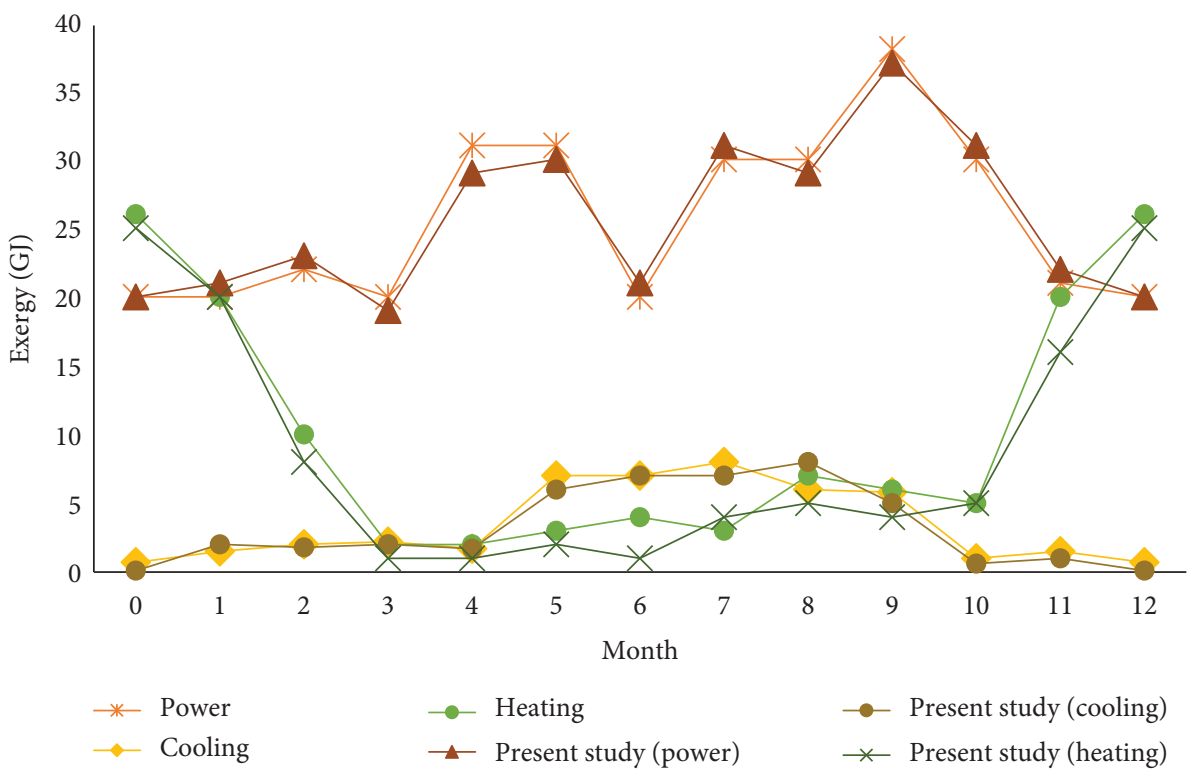

FIgURE 5: Verification charts of exergy analysis results.

TABLE 6: Collectors with different percentages of nanofluids and porous media.

Simple parabolic solar collectors

Parabolic solar collectors with fully filled porous media

Parabolic solar collectors with fully filled porous media and 0.1 percent $\mathrm{CuO}$ Parabolic solar collectors with fully filled porous media and 0.1 percent $\mathrm{Al}_{2} \mathrm{O}_{3}$ Parabolic solar collectors with fully filled porous media and 0.2 percent $\mathrm{CuO}$ Parabolic solar collectors with fully filled porous media and 0.2 percent $\mathrm{Al}_{2} \mathrm{O}_{3}$ Parabolic solar collectors with fully filled porous media and 0.3 percent $\mathrm{CuO}$ Parabolic solar collectors with fully filled porous media and 0.3 percent $\mathrm{Al}_{2} \mathrm{O}_{3}$ Parabolic solar collectors with fully filled porous media and 0.4 percent $\mathrm{CuO}$ Parabolic solar collectors with fully filled porous media and 0.4 percent $\mathrm{Al}_{2} \mathrm{O}_{3}$ Parabolic solar collectors with fully filled porous media and 0.5 percent $\mathrm{CuO}$ Parabolic solar collectors with fully filled porous media and 0.5 percent $\mathrm{Al}_{2} \mathrm{O}_{3}$ Parabolic solar collectors with fully filled porous media and 0.6 percent $\mathrm{CuO}$ Parabolic solar collectors with fully filled porous media and 0.56 percent $\mathrm{Al}_{2} \mathrm{O}_{3}$ 


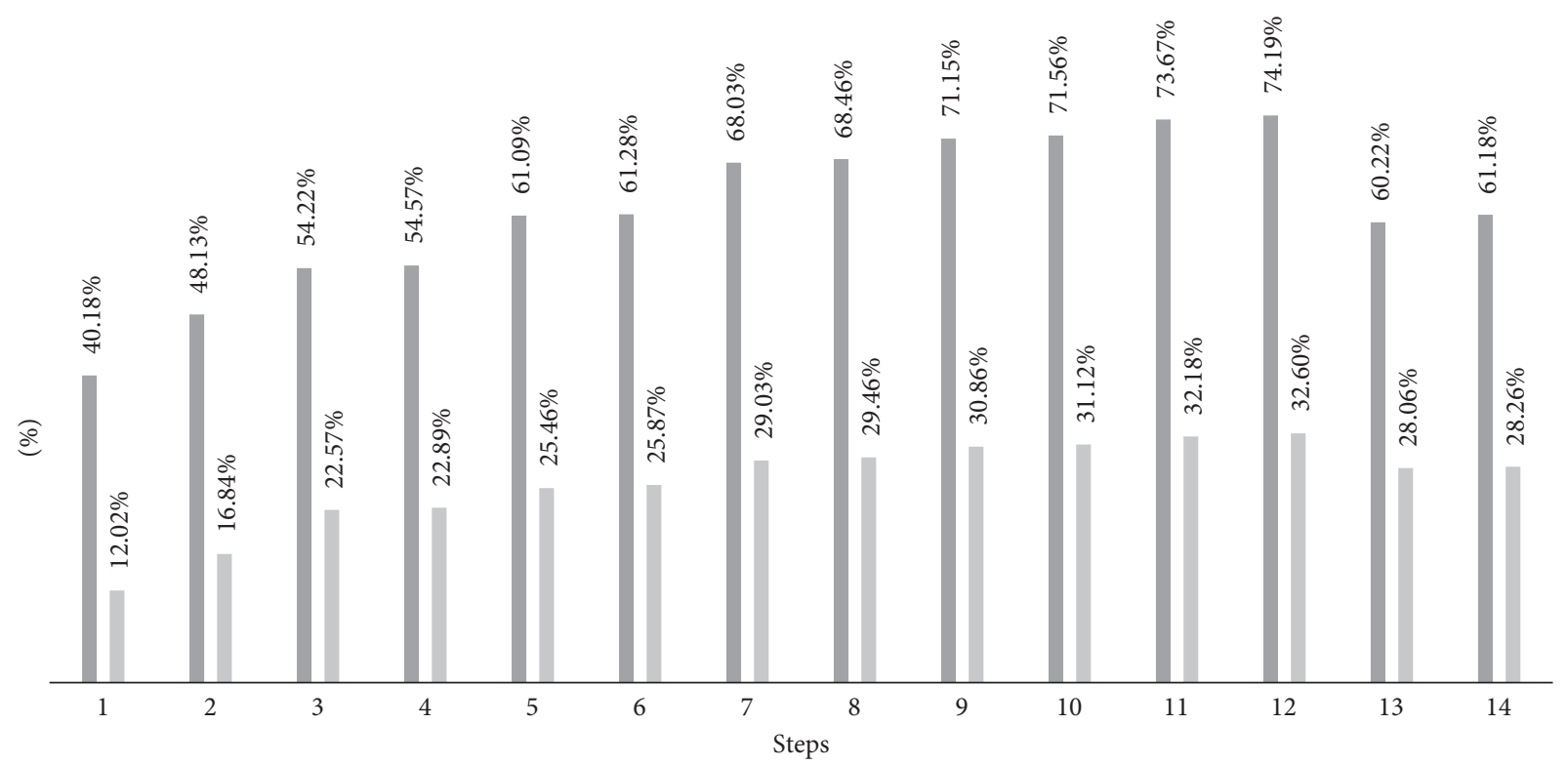

PTC collector system energy efficiency

PTC collector system exergy efficiency

FIgURE 6: Energy and exergy efficiencies of the PTC with porous media and nanofluid.

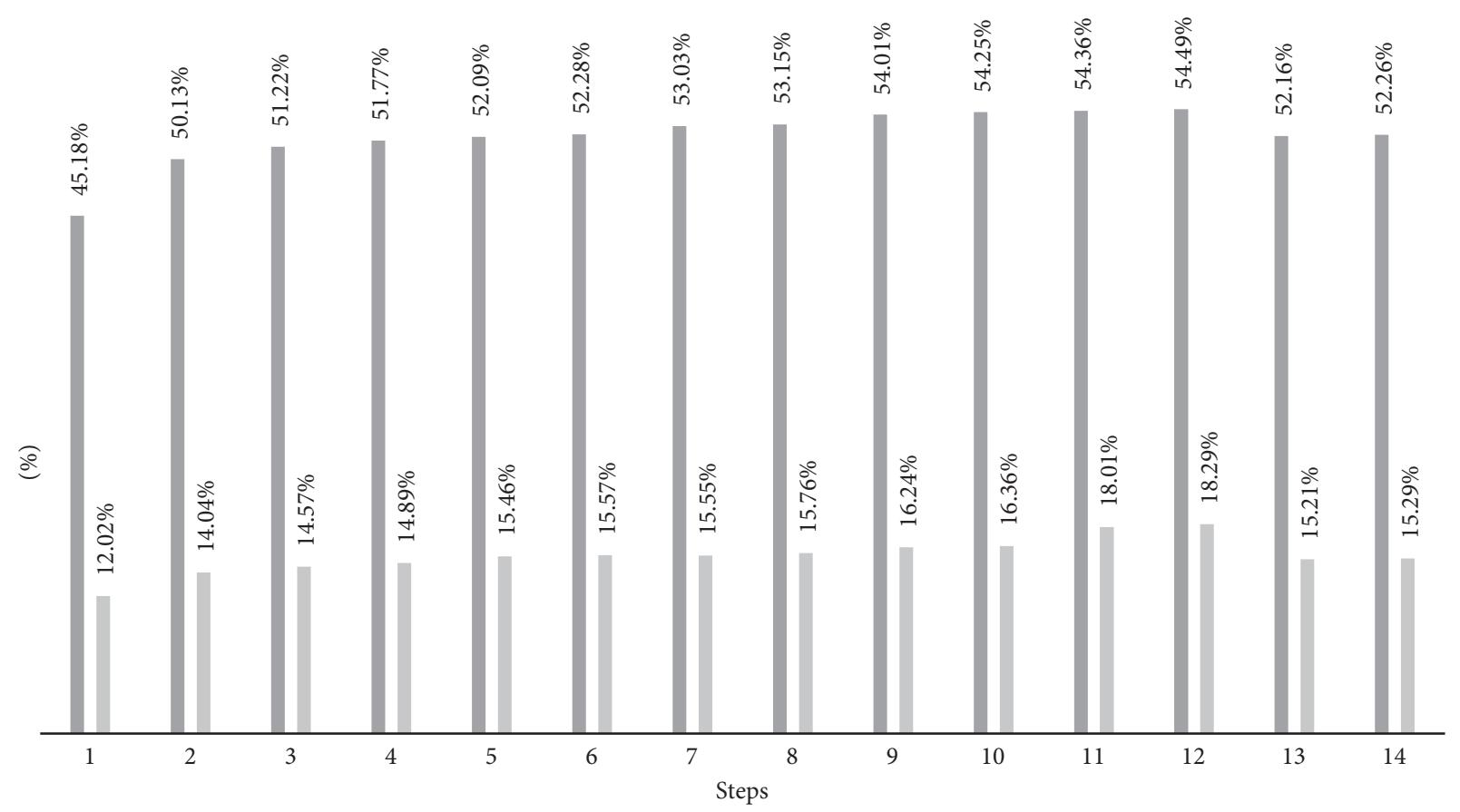

SCCHP system energy efficiency

SCCHP system exergy efficiency

FIGURE 7: Energy and exergy efficiency of the SCCHP. 
low temperature is $0.5 \%\left(\mathrm{AL}_{2} \mathrm{O}_{3}\right.$ and $\left.\mathrm{CUO}\right)$; with this replacement, the cost of solar collectors and SCCHP cycle is reduced.

\section{Conclusion and Future Directions}

In the present study, ways for increasing the efficiency of solar collectors in order to enhance the efficiency of the SCCHP cycle are examined. The research is aimed at adding both porous materials and nanofluids for estimating the best ratio of nanofluid for enhanced solar collector and protecting sedimentation in porous media. By adding porous materials (copper foam with porosity of $95 \%$ ) and $0.5 \%$ nanofluids together, high efficiency in solar parabolic collectors can be achieved. The novelty in this research is the addition of both nanofluids and porous materials and calculating the best ratio for preventing sedimentation and pressure drop in solar collector's pipe. In this study, it was observed that, by adding $0.5 \%$ of $\mathrm{AL}_{2} \mathrm{O}_{3}$ nanofluid in working fluids, the energy efficiency of PTC rises to $74.19 \%$ and exergy efficiency is grown up to $32.6 \%$. In SCCHP cycle, energy efficiency is $54.49 \%$ and exergy efficiency is $18.29 \%$.

In this research, parabolic solar collectors fully filled by porous media (copper foam with a porosity of 95) are investigated. In the next step, parabolic solar collectors in the SCCHP cycle were simultaneously filled by porous media and different percentages of $\mathrm{Al}_{2} \mathrm{O}_{3}$ and $\mathrm{CuO}$ nanofluid. At this step, values of $0.1 \%$ to $0.6 \%$ of each nanofluid were added to the working fluid, and the efficiency of the energy and exergy of the collectors and the SCCHP cycle were determined. In this case, nanofluid and the porous media were used together in the solar collector and maximum efficiency achieved. $0.5 \%$ of both nanofluids were used to achieve the biggest efficiency enhancement.

In the present study, as expected, the highest efficiency is for the parabolic solar collector fully filled by porous material (copper foam with a porosity of $95 \%$ ) and $0.5 \% \mathrm{Al}_{2} \mathrm{O}_{3}$. Results of the present study are as follows:

(1) The average enhancement of collectors' efficiency using porous media and nanofluids is $28 \%$.

(2) Solutions with 0.1 to $0.5 \%$ of nanofluids $(\mathrm{CuO}$ and $\mathrm{Al}_{2} \mathrm{O}_{3}$ ) are used to prevent collectors from sediment occurrence in porous media.

(3) Collector of solar cogeneration cycles that is enhanced by both porous media and nanofluid has higher efficiency, and the stability of output temperature is more as well.

(4) By using $0.6 \%$ of the nanofluids in the enhanced parabolic solar collectors with copper porous materials, sedimentation occurs and makes a highpressure drop in the solar collector's pipe which causes decrease in energy efficiency.

(5) Average enhancement of SCCHP cycle efficiency is enhanced by both porous media and nanofluid $13 \%$.

\section{Nomenclature}

$I_{b}: \quad$ Solar radiation

a: $\quad$ Heat transfer augmentation coefficient

A: $\quad$ Solar collector area

Bf: $\quad$ Basic fluid

$c_{p . n f}: \quad$ Specific heat capacity of the nanofluid

$F: \quad$ Constant of air dilution

$k_{n f}: \quad$ Thermal conductivity of the nanofluid

$k_{b f}$ : Thermal conductivity of the basic fluid

$\mu_{n f}: \quad$ Viscosity of the nanofluid

$\mu_{b f}: \quad$ Viscosity of the basic fluid

$\eta_{c}: \quad$ Collector efficiency

$\dot{Q}_{c}: \quad$ Collector energy receives

$\dot{Q}_{b}: \quad$ Auxiliary boiler heat

$\dot{Q}_{\exp }: \quad$ Expander energy

$\dot{Q}_{g}: \quad$ Gas energy

$\dot{w}_{\text {exp }}: \quad$ Screw expander work

$\dot{Q}_{\text {cool }}: \quad$ Cooling load, in kilowatts

$\dot{Q}_{\text {Heat }}: \quad$ Heating load, in kilowatts

$\dot{Q}_{s}: \quad$ Solar radiation energy on collector, in Joule

$Q_{\text {hotwater: Sanitary hot water load }}$

Np: $\quad$ Nanoparticle

$\eta_{e}: \quad$ Energy efficiency

$\eta_{\mathrm{HE}}: \quad$ Heat exchanger efficiency

$\mathrm{xE}_{s}: \quad$ Sun exergy

x $\dot{E}_{c}: \quad$ Collector exergy

$\mathrm{x}_{G}: \quad$ Natural gas exergy

$\mathrm{x} \dot{E_{\text {exp }}}: \quad$ Expander exergy

$\dot{E}_{\text {xcool }}$ : Cooling exergy

$\dot{E}_{\text {xheat }}$ : Heating exergy

$\eta_{\text {ex }}: \quad$ Exergy efficiency

$\dot{m}_{\mathrm{st}}: \quad$ Steam mass flow rate

$\dot{m}_{\text {hotwater }}$ : Hot water mass flow rate

$C_{p W}: \quad$ Specific heat capacity of water

$\dot{w}_{\text {exp }}$ : $\quad$ Power output form by the screw expander

$T_{\mathrm{am}}$ : $\quad$ Average ambient temperature

$\rho_{n f}$ : Density of the mixture.

\section{Greek symbols}

$\rho$ : Density

$\phi$ : Nanoparticles volume fraction

$\beta$ : Ratio of the nanolayer thickness.

\section{Abbreviations}

CCHP: Combined cooling, heating, and power

EES: Engineering equation solver.

\section{Data Availability}

For this study, data were generated by CARRIER software for the average electrical, heating, and cooling load of a residential building with $600 \mathrm{~m}^{2}$ in the city of Zahedan, Iran.

\section{Conflicts of Interest}

The authors declare that they have no conflicts of interest. 


\section{Acknowledgments}

This work was partially supported by the National Natural Science Foundation of China under Contract no. 71761030 and Natural Science Foundation of Inner Mongolia under Contract no. 2019LH07003.

\section{References}

[1] A. Fudholi and K. Sopian, "Review on solar collector for agricultural produce," International Journal of Power Electronics and Drive Systems (IJPEDS), vol. 9, no. 1, p. 414, 2018.

[2] G. Yang and X. Zhai, "Optimization and performance analysis of solar hybrid CCHP systems under different operation strategies," Applied Thermal Engineering, vol. 133, pp. 327340, 2018.

[3] J. Wang, Z. Han, and Z. Guan, "Hybrid solar-assisted combined cooling, heating, and power systems: a review," Renewable and Sustainable Energy Reviews, vol. 133, p. 110256, 2020.

[4] Y. Tian and C. Y. Zhao, "A review of solar collectors and thermal energy storage in solar thermal applications," Applied Energy, vol. 104, pp. 538-553, 2013.

[5] J. M. Hassan, Q. J. Abdul-Ghafour, and M. F. Mohammed, "CFD simulation of enhancement techniques in flat plate solar water collectors," Al-Nahrain Journal for Engineering Sciences, vol. 20, no. 3, pp. 751-761, 2017.

[6] M. Jahangiri, O. Nematollahi, A. Haghani, H. A. Raiesi, and A. Alidadi Shamsabadi, "An optimization of energy cost of clean hybrid solar-wind power plants in Iran," International Journal of Green Energy, vol. 16, no. 15, pp. 1422-1435, 2019.

[7] I. H. Yilmaz and A. Mwesigye, "Modeling, simulation and performance analysis of parabolic trough solar collectors: a comprehensive review," Applied Energy, vol. 225, pp. 135-174, 2018.

[8] F. Wang, J. Tan, and Z. Wang, "Heat transfer analysis of porous media receiver with different transport and thermophysical models using mixture as feeding gas," Energy Conversion and Management, vol. 83, pp. 159-166, 2014.

[9] H. Zhai, Y. J. Dai, J. Y. Wu, and R. Z. Wang, "Energy and exergy analyses on a novel hybrid solar heating, cooling and power generation system for remote areas," Applied Energy, vol. 86, no. 9, pp. 1395-1404, 2009.

[10] M. H. Abbasi, H. Sayyaadi, and M. Tahmasbzadebaie, "A methodology to obtain the foremost type and optimal size of the prime mover of a CCHP system for a large-scale residential application," Applied Thermal Engineering, vol. 135, pp. 389-405, 2018.

[11] R. Jiang, F. G. F. Qin, X. Yang, S. Huang, and B. Chen, "Performance analysis of a liquid absorption dehumidifier driven by jacket-cooling water of a diesel engine in a CCHP system," Energy and Buildings, vol. 163, pp. 70-78, 2018.

[12] F. A. Boyaghchi and M. Chavoshi, "Monthly assessments of exergetic, economic and environmental criteria and optimization of a solar micro-CCHP based on DORC," Solar Energy, vol. 166, pp. 351-370, 2018.

[13] F. A. Boyaghchi and M. Chavoshi, "Multi-criteria optimization of a micro solar-geothermal CCHP system applying water/CuO nanofluid based on exergy, exergoeconomic and exergoenvironmental concepts," Applied Thermal Engineering, vol. 112, pp. 660-675, 2017.

[14] B. Su, W. Han, Y. Chen, Z. Wang, W. Qu, and H. Jin, "Performance optimization of a solar assisted CCHP based on biogas reforming," Energy Conversion and Management, vol. 171, pp. 604-617, 2018.

[15] F. A. Al-Sulaiman, F. Hamdullahpur, and I. Dincer, "Performance assessment of a novel system using parabolic trough solar collectors for combined cooling, heating, and power production," Renewable Energy, vol. 48, pp. 161-172, 2012.

[16] J. Wang, Y. Dai, L. Gao, and S. Ma, "A new combined cooling, heating and power system driven by solar energy," Renewable Energy, vol. 34, no. 12, pp. 2780-2788, 2009.

[17] Y.-Y. Jing, H. Bai, J.-J. Wang, and L. Liu, "Life cycle assessment of a solar combined cooling heating and power system in different operation strategies," Applied Energy, vol. 92, pp. 843-853, 2012.

[18] J.-J. Wang, Y.-Y. Jing, and C.-F. Zhang, "Optimization of capacity and operation for CCHP system by genetic algorithm," Applied Energy, vol. 87, no. 4, pp. 1325-1335, 2010.

[19] L. Ali, "LDA-GA-SVM: improved hepatocellular carcinoma prediction through dimensionality reduction and genetically optimized support vector machine," Neural Computing and Applications, vol. 87, pp. 1-10, 2020.

[20] S. Hirasawa, R. Tsubota, T. Kawanami, and K. Shirai, "Reduction of heat loss from solar thermal collector by diminishing natural convection with high-porosity porous medium," Solar Energy, vol. 97, pp. 305-313, 2013.

[21] E. Bellos, C. Tzivanidis, and Z. Said, "A systematic parametric thermal analysis of nanofluid-based parabolic trough solar collectors," Sustainable Energy Technologies and Assessments, vol. 39, p. 100714, 2020.

[22] H. J. Jouybari, S. Saedodin, A. Zamzamian, M. E. Nimvari, and S. Wongwises, "Effects of porous material and nanoparticles on the thermal performance of a flat plate solar collector: an experimental study," Renewable Energy, vol. 114, pp. 14071418, 2017.

[23] J. Subramani, P. K. Nagarajan, S. Wongwises, S. A. El-Agouz, and R. Sathyamurthy, "Experimental study on the thermal performance and heat transfer characteristics of solar parabolic trough collector using $\mathrm{Al}_{2} \mathrm{O}_{3}$ nanofluids," Environmental Progress \& Sustainable Energy, vol. 37, no. 3, pp. 1149-1159, 2018.

[24] E. Shojaeizadeh, F. Veysi, and A. Kamandi, "Exergy efficiency investigation and optimization of an $\mathrm{Al}_{2} \mathrm{O}_{3}$-water nanofluid based Flat-plate solar collector," Energy and Buildings, vol. 101, pp. 12-23, 2015.

[25] A. K. Tiwari, P. Ghosh, and J. Sarkar, "Solar water heating using nanofluids-a comprehensive overview and environmental impact analysis," International Journal of Emerging Technology and Advanced Engineering, vol. 3, no. 3, pp. 221-224, 2013.

[26] D. R. Rajendran, E. Ganapathy Sundaram, P. Jawahar, V. Sivakumar, O. Mahian, and E. Bellos, "Review on influencing parameters in the performance of concentrated solar power collector based on materials, heat transfer fluids and design," Journal of Thermal Analysis and Calorimetry, vol. 140, no. 1, pp. 33-51, 2020.

[27] M. Feizbahr, C. Kok Keong, F. Rostami, and M. Shahrokhi, "Wave energy dissipation using perforated and non perforated piles," International Journal of Engineering, vol. 31, no. 2, pp. 212-219, 2018.

[28] K. Khanafer and K. Vafai, "A critical synthesis of thermophysical characteristics of nanofluids," International Journal of Heat and Mass Transfer, vol. 54, no. 19-20, pp. 4410-4428, 2011.

[29] K. Farhana, K. Kadirgama, M. M. Rahman et al., "Improvement in the performance of solar collectors with 
nanofluids - a state-of-the-art review," Nano-Structures \& Nano-Objects, vol. 18, p. 100276, 2019.

[30] M. Turkyilmazoglu, "Condensation of laminar film over curved vertical walls using single and two-phase nanofluid models," European Journal of Mechanics-B/Fluids, vol. 65, pp. 184-191, 2017.

[31] X. Zhang, J. Wang, T. Wang, R. Jiang, J. Xu, and L. Zhao, "Robust feature learning for adversarial defense via hierarchical feature alignment," Information Sciences, vol. 2020, 2020.

[32] X. Zhang, T. Wang, W. Luo, and P. Huang, "Multi-level fusion and attention-guided CNN for image dehazing," IEEE Transactions on Circuits and Systems for Video Technology, vol. 1, 2020.

[33] X. Zhang, M. Fan, D. Wang, P. Zhou, and D. Tao, “Top- $k$ feature selection framework using robust 0-1 integer programming," IEEE Transactions on Neural Networks and Learning Systems, vol. 1, pp. 1-15, 2020.

[34] X. Zhang, D. Wang, Z. Zhou, and Y. Ma, "Robust low-rank tensor recovery with rectification and alignment," IEEE Transactions on Pattern Analysis and Machine Intelligence, vol. 43, no. 1, pp. 238-255, 2019.

[35] X. Zhang, R. Jiang, T. Wang, and J. Wang, "Recursive neural network for video deblurring," IEEE Transactions on Circuits and Systems for Video Technology, vol. 1, 2020.

[36] X. Zhang, T. Wang, J. Wang, G. Tang, and L. Zhao, "Pyramid channel-based feature attention network for image dehazing," Computer Vision and Image Understanding, vol. 1, 2020.

[37] M. Mirmozaffari, "Machine learning algorithms based on an optimization model," 2020.

[38] M. Mirmozaffari, M. Yazdani, A. Boskabadi, H. Ahady Dolatsara, K. Kabirifar, and N. Amiri Golilarz, "A novel machine learning approach combined with optimization models for eco-efficiency evaluation," Applied Sciences, vol. 10, no. 15, p. 5210, 2020

[39] M. Vosoogha and A. Addeh, "An intelligent power prediction method for wind energy generation based on optimized fuzzy system," Computational Research Progress in Applied Science \& Engineering (CRPASE), vol. 5, pp. 34-43, 2019.

[40] A. Javadi, N. Mikaeilvand, and H. Hosseinzdeh, "Presenting a new method to solve partial differential equations using a group search optimizer method (GSO)," Computational Research Progress in Applied Science and Engineering, vol. 4, no. 1, pp. 22-26, 2018.

[41] F. J. Golrokh, Gohar Azeem, and A. Hasan, "Eco-efficiency evaluation in cement industries: DEA malmquist productivity index using optimization models," ENG Transactions, vol. 1, pp. 1-8, 2020.

[42] H. Yu, "Dynamic Gaussian bare-bones fruit fly optimizers with abandonment mechanism: method and analysis," Engineering with Computers, vol. 1, pp. 1-29, 2020.

[43] C. Yu, "SGOA: annealing-behaved grasshopper optimizer for global tasks," Engineering with Computers, vol. 1, pp. 1-28, 2021.

[44] W. Shan, Z. Qiao, A. A. Heidari, H. Chen, H. Turabieh, and Y. Teng, "Double adaptive weights for stabilization of moth flame optimizer: balance analysis, engineering cases, and medical diagnosis," Knowledge-Based Systems, vol. 1, p. 106728, 2020.

[45] J. Tu, H. Chen, J. Liu et al., "Evolutionary biogeography-based whale optimization methods with communication structure: towards measuring the balance," Knowledge-Based Systems, vol. 212, p. 106642, 2021.
[46] Y. Zhang, "Towards augmented kernel extreme learning models for bankruptcy prediction: algorithmic behavior and comprehensive analysis," Neurocomputing, vol. 1, 2020.

[47] Y. Zhang, R. Liu, X. Wang, H. Chen, and C. Li, "Boosted binary Harris hawks optimizer and feature selection," Engineering with Computers, vol. 1, pp. 1-30, 2020.

[48] H.-L. Chen, G. Wang, C. Ma, Z.-N. Cai, W.-B. Liu, and S.-J. Wang, "An efficient hybrid kernel extreme learning machine approach for early diagnosis of Parkinson's disease," Neurocomputing, vol. 184, pp. 131-144, 2016.

[49] L. Hu, G. Hong, J. Ma, X. Wang, and H. Chen, "An efficient machine learning approach for diagnosis of paraquat-poisoned patients," Computers in Biology and Medicine, vol. 59, pp. 116-124, 2015.

[50] L. Shen, H. Chen, Z. Yu et al., "Evolving support vector machines using fruit fly optimization for medical data classification," Knowledge-Based Systems, vol. 96, pp. 61-75, 2016.

[51] J. Xia, H. Chen, Q. Li et al., "Ultrasound-based differentiation of malignant and benign thyroid Nodules: an extreme learning machine approach," Computer Methods and Programs in Biomedicine, vol. 147, pp. 37-49, 2017.

[52] C. Li, L. Hou, B. Y. Sharma et al., "Developing a new intelligent system for the diagnosis of tuberculous pleural effusion," Computer Methods and Programs in Biomedicine, vol. 153, pp. 211-225, 2018.

[53] X. Zhao, X. Zhang, Z. Cai et al., "Chaos enhanced grey wolf optimization wrapped ELM for diagnosis of paraquat-poisoned patients," Computational Biology and Chemistry, vol. 78, pp. 481-490, 2019.

[54] M. Wang and H. Chen, "Chaotic multi-swarm whale optimizer boosted support vector machine for medical diagnosis," Applied Soft Computing Journal, vol. 88, 2020.

[55] X. Xu and H.-L. Chen, "Adaptive computational chemotaxis based on field in bacterial foraging optimization," Soft Computing, vol. 18, no. 4, pp. 797-807, 2014.

[56] R. U. Khan, X. Zhang, R. Kumar, A. Sharif, N. A. Golilarz, and M. Alazab, "An adaptive multi-layer botnet detection technique using machine learning classifiers," Applied Sciences, vol. 9, no. 11, p. 2375, 2019.

[57] A. Addeh, A. Khormali, and N. A. Golilarz, "Control chart pattern recognition using RBF neural network with new training algorithm and practical features," ISA Transactions, vol. 79, pp. 202-216, 2018.

[58] N. Amiri Golilarz, H. Gao, R. Kumar, L. Ali, Y. Fu, and C. Li, "Adaptive wavelet based MRI brain image de-noising," Frontiers in Neuroscience, vol. 14, p. 728, 2020.

[59] N. A. Golilarz, H. Gao, and H. Demirel, "Satellite image denoising with Harris hawks meta heuristic optimization algorithm and improved adaptive generalized Gaussian distribution threshold function," IEEE Access, vol. 7, pp. 57459-57468, 2019.

[60] M. Eisazadeh and J. Rezapour, "Multi-objective optimization of the composite sheets using PSO algorithm," 2017.

[61] I. Bargegol, M. Nikookar, R. V. Nezafat, E. J. Lashkami, and A. M. Roshandeh, "Timing optimization of signalized intersections using shockwave theory by genetic algorithm," Computational Research Progress in Applied Science \& Engineering, vol. 1, pp. 160-167, 2015.

[62] B. Bai, Z. Guo, C. Zhou, W. Zhang, and J. Zhang, "Application of adaptive reliability importance sampling-based extended domain PSO on single mode failure in reliability engineering," Information Sciences, vol. 546, pp. 42-59, 2021.

[63] J. Liu, C. Wu, G. Wu, and X. Wang, "A novel differential search algorithm and applications for structure design," 
Applied Mathematics and Computation, vol. 268, pp. 246-269, 2015.

[64] X. Zhao, D. Li, B. Yang, C. Ma, Y. Zhu, and H. Chen, "Feature selection based on improved ant colony optimization for online detection of foreign fiber in cotton," Applied Soft Computing, vol. 24, pp. 585-596, 2014.

[65] D. Zhao, "Chaotic random spare ant colony optimization for multi-threshold image segmentation of 2D Kapur entropy," Knowledge-Based Systems, vol. 24, p. 106510, 2020.

[66] H. Chen, A. A. Heidari, H. Chen, M. Wang, Z. Pan, and A. H. Gandomi, "Multi-population differential evolutionassisted Harris hawks optimization: framework and case studies," Future Generation Computer Systems, vol. 111, pp. 175-198, 2020.

[67] J. Hu, H. Chen, A. A. Heidari et al., "Orthogonal learning covariance matrix for defects of grey wolf optimizer: insights, balance, diversity, and feature selection," Knowledge-Based Systems, vol. 213, p. 106684, 2021.

[68] G. Sun, B. Yang, Z. Yang, and G. Xu, "An adaptive differential evolution with combined strategy for global numerical optimization," Soft Computing, vol. 24, pp. 1-20, 2019.

[69] G. Sun, C. Li, and L. Deng, "An adaptive regeneration framework based on search space adjustment for differential evolution," Neural Computing and Applications, vol. 24, pp. 1-17, 2021.

[70] A. Addeh and M. Iri, "Brain tumor type classification using deep features of MRI images and optimized RBFNN," ENG Transactions, vol. 2, pp. 1-7, 2021.

[71] F. J. Golrokh and A. Hasan, "A comparison of machine learning clustering algorithms based on the DEA optimization approach for pharmaceutical companies in developing countries," Soft Computing, vol. 1, pp. 1-8, 2020.

[72] H. Tyagi, P. Phelan, and R. Prasher, "Predicted efficiency of a low-temperature nanofluid-based direct absorption solar collector," Journal of Solar Energy Engineering, vol. 131, no. 4, 2009.

[73] S. Rashidi, M. Bovand, and J. A. Esfahani, "Heat transfer enhancement and pressure drop penalty in porous solar heat exchangers: a sensitivity analysis," Energy Conversion and Management, vol. 103, pp. 726-738, 2015.

[74] N. Akram, R. Sadri, S. N. Kazi et al., "A comprehensive review on nanofluid operated solar flat plate collectors," Journal of Thermal Analysis and Calorimetry, vol. 139, no. 2, pp. 13091343, 2020. 